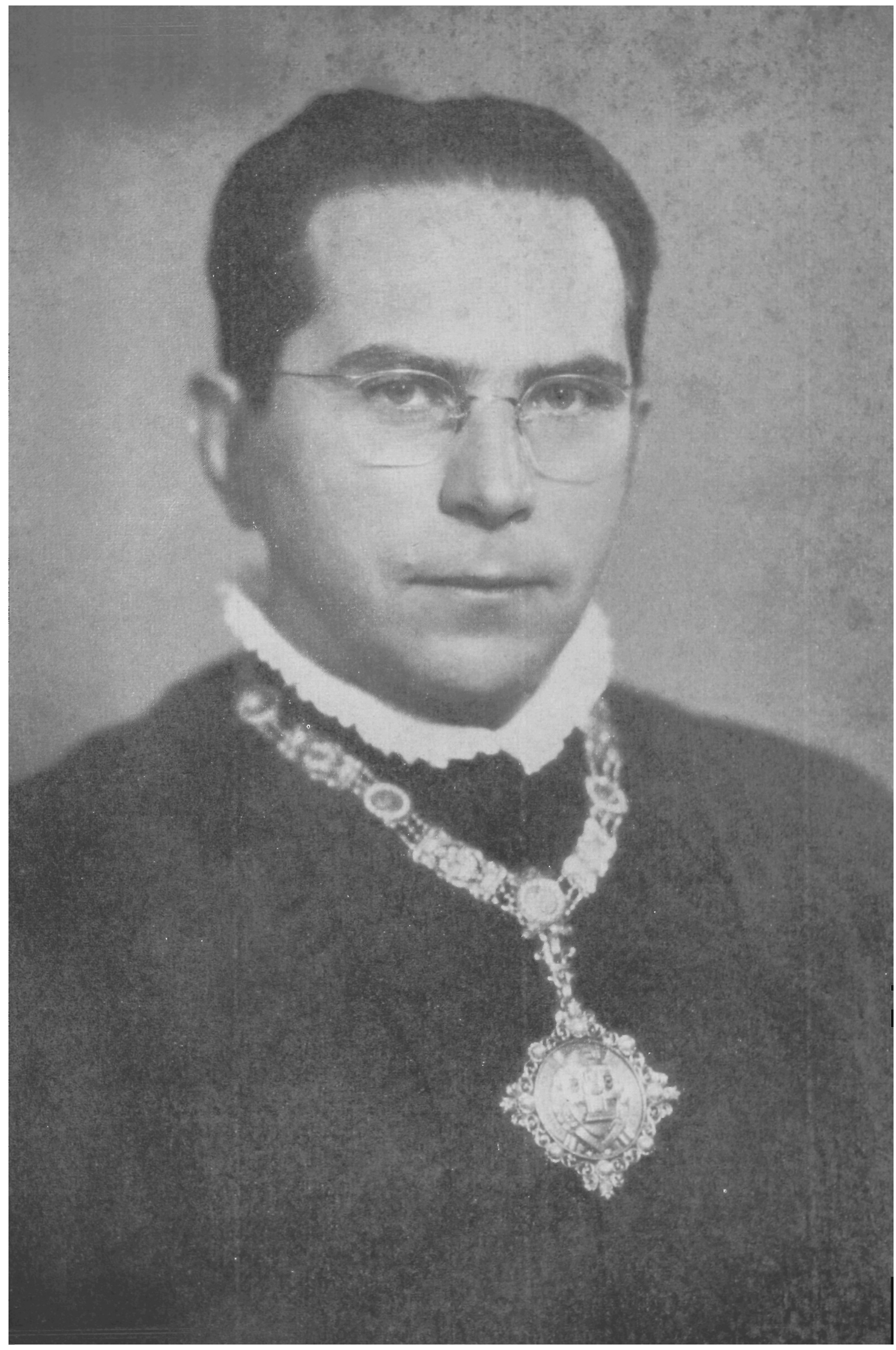


Frof. Dr. Mrguel Reale quando Reitor da Universidade de São Paulo. 


\title{
Miguel Reale
}

\author{
Professor Catedrático de Filosofia do Direito \\ na Universidade de São Paulo.
}

O Professor Miguel Reale nasceu em São Bento do Sapucaí, Estado de São Paulo, Brasil, em 6 de novembro de 1910, sendo filho do Dr. Braz Reale e de D. ${ }^{\text {a Felicidade }}$ Chiaradia Reale. Foram seus avós paternos Afonso Reale e D. ${ }^{a}$ Teresa Giondano e maternos Miguel Chiaradia e D. Ana Ferreira da Rosa. Fêz seus estudos primários em Itajubá, Estado de Minas Gerais, no Colégio de Nossa Senhora da Glória, e os secundários na Capital do Estado, no Instituto Médio Dante Alighieri, onde ingressou em 1922 e se diplomou em 1929.

Em 1930, matriculou-se na Faculdade de Direito de São Paulo, colando grau de bacharel em ciências jurídicas e sociais, no dia 16 de agôsto de 1934. Tomou parte ativa nas festividades e comemorações acadêmicas, colaborando na Revista XI de Agôsto, e em outros órgãos estudantís. Foi, durante todo o curso acadêmico, vice-presidente da Liga Acadêmica, e, no último ano, foi eleito para a Academia de Letras da Faculdade.

Ainda nos bancos acadêmicos desenvolveu intensa atividade política, sendo indicado por seus correligionários para candidato à Constituinte de 1933 , tendo escrito, então, o primeiro de seus livros, O Estado Moderno, que só veio à luz em julho de 1934, alcançando desde logo três edições.

Lecionou primeiramente, latim e psicologia no curso pré-jurídico organizado pela Liga Acadêmica, e foi um dos diretores do Ateneu Graça Aranha, em cujo curso comercial lecionou Direito Comercial e Legislação Fiscal até 1936. 
Em janeiro de 1936, fundou a revista mensal Panorama, da qual foi diretor até fins de 1937. Essa revista foi o centro do pensamento político do Integralismo brasilciro.

Em 7 de outubro de 1936, iniciou a publicação, em São Paulo, do diário Ação, do qual foi diretor até 23 de abril de 1938.

No período de 1935 a 1936 , dirigiu um curso de Sociologia e História da Filosofia, no Instituto Paulista de Alta Cultura.

Não obstante a sua atividade no jornalismo, na política e no ensino, publicou sete volumes no período de 1934 a 1937, versando sôbre problemas fundamentais de Filosofia, História, Sociologia, Direito e Economia. São dêsse período o já citado O Estado Moderno, Formação da Política Burguesa, sôbre as bases filosóficas da política a partir do Renascimento, $O$ Capitalisino Internacional, Atualidade de um Mundo Antigo e Atualidades Brasileiras.

Em maio de 1940, inscreveu-se no concurso para professor catedrático de Filosofia no Direito na Faculdade de Direito da Universidade de São Paulo, apresentando a tese Fundamentos do Direito.

Antes de iniciado o concurso, deu à publicidade em 1940 a obra Teoria do Direito e do Estado, da qual apareceu a 2. ${ }^{a}$ edição em 1962.

Classificado em primeiro lugar no concurso acima referido, foi nomeado professor catedrático de Filosofia do Direito, por decreto do govêrno estadual de 6 de maio de 1941, e tomou posse em sessão solene da Congregação da Faculdade, realizada em 14 de maio de 1941. É afualmente também professor da disciplina no "Curso de Especialização".

Em 1942 foi nomeado para o "Conselho Administrativo" do Estado de São Paulo, tendo exercido as funções de Conselheiro de Estado até 1945. 
Secretário da Justiça e dos Negócios Interiores em 1947. sempre no Estado de São Paulo, organizou diversos órgãos fundamentais da administração, como, por exemplo, o "Departamento Jurídico do Estado" e a "Assessoria TécnicoLegislativa".

Em 1949, foi nomeado Reitor da Universidade de São Paulo, cargo que exerceu até 1950, reestruturando diversos de seus departamentos e institutos e traçando o primeiro plano de expansão universitária no interior do Estado.

Seus últimos trabalhos fundamentais de natureza filosófico-jurídica ou filosófica são: A Doutrina de Kant no Brasil 1952; Filosofia do Direito, 1953, já agora na $4 .^{\text {a }}$ edição; Horizontes do Direito e da História, 1956, Filosofia em São Paulo, 1962; Pluralismo e Liberdade, 1963. Do seu curso de Filosofia do Direito há tradução italiana feita pelos Professôres - Luigr Bagolini e Ricci, da Universidade de Genova, 1957.

Além de constante colaboração em diversas revistas de Filosofia e de Direito, foi convidado para colaborar nos volumes publicados em homenagem a Paulo Roubier, Jean Dabin, Legaz y Lacambra e Roscoe Pound.

É um dos diretores da Revista da Faculdade de Direito da Universidade de São Paulo.

Advogado militante, tem escrito dezenas de trabalhos forenses e pareceres, destacando-se os seguintes estudos: Da exclusão dos sócios das sociedades mercantis, Da exclusão dos sócios das associações civis, Da intervenção do Estado na vida econômica, Natureza jurídica da criação dos municipios, Da recorribilidade dos atos dos administradores das autarquias, As autarquias universitárias paulistas, Do município e do direito sôbre seu território, reunidos com outros mais no volume Nos Quadrantes do Direito Positivo, 1960.

Em 1949, fundou o Instituto Brasileiro de Filosofia, do qual é presidente, promovendo a realização de três Congressos Nacionais de Filosofia e de um Internacional, êste comemorativo do IV Centenário da Cidade de São Paulo, 
em 1954. Promoveu a publicação dos 3 tomos das Atas do referido certame.

Em 1951, fundou, como presidente do I.B.F. a Revista Brasileira de Filosofia, já em seu $63 .^{\circ}$ fascículo trimestral, constituindo hoje em dia o maior repositório do pensamento filosófico brasileiro.

Sócio fundador da Sociedade Interamericana de Filosofia, foi o seu primeiro presidente, eleito pelos instituidores da entidade membro permanente da Comissão Diretora.

É membro correspondente de várias instituições culturais, dentre as quais a Academia das Ciências da Universidade de Bolonha, da Sociedade Argentina de Filosofia e do Instituto Argentino de Filosofia Jurídica e Social; é sócio honorário da Sociedade Italiana de Filosofia do Direito, bem como da Sociedade Mexicana de Filosofia e da Sociedade Espanhola de Filosofia do Direito.

Foi escolhido pelos organizadores do XII Congresso Internacional de Filosofia, realizado em Veneza, para ser um dos dez relatores gerais do certame, cabendo-lhe a missão de relatar o tema Liberdade e Valor. Representou o Brasil em diversos Congressos Internacionais de Filosofia, como os de Santiago do Chile, Washington, Buenos Aires e São José da Costa Rica, cabendo-lhe uma das vice-presidências de todos êsses certames. Participou também, como convidado especial, do Congresso de Estudos Humanísticos de Roma, em 1952, onde apresentou um trabalho intitulado Cristianismo e razão de Estado no Renascimento lusiada.

Em julho de 1951, foi Delegado do Govêrno Brasileiro junto à Conferência da Organização Internacional do Trabalho (O.I.T.) em Genebra.

Presidente do III Congresso Nacional de Filosofia, recebeu, neste certame o título de "benemérito da cultura nacional."

É, atualmente, membro do Conselho Estadual de Educação e da Comissão Editorial da Universidade de São Paulo. 


\section{Bibliografia fundamental de Miguel Reale.}

\section{Obras de Filosofia e de Filosofia do Direito.}

Fundamentos do Direito, "Tese de Concurso à Cátedra de Filosofia do Direito", São Paulo, 1940.

o Conceito de "Ratio Naturalis" entre os Jurisconsultos Romanos e Santo Tomás de Aquino na "Revista da Faculdade de Direito", v. 38, p. 107-117, São Paulo, 1942.

o Contratualismo. Posição de Rousseau e Kant. Emprêsa Gráfica da Revista dos Tribunais Ltda., São Paulo, 1943.

Nietzche e o valor da Filosofia; em "Arcadia”, n. 24, p. 15, São Paulo, 1944.

Posição de Rui Barbosa no Mundo da Filosofia. Subsidios para compreensão de uma Trajetória Espiritual. Casa de Rui Barbosa, Rio de Janeiro, 1949.

Doutrina de Kant no Brasil. São Paulo, 1949.

Feijó e o Kantismo, na "Revista da Faculdade de Direito", v. 45, p. 330-351, São Paulo, 1950.

Cristianesimo e Ragion di Stato nel Rinascimento Lusitano, nos "Atti del Congresso Internazionale di Studi Umanistici", Pavia, 1952, p. 133-159.

A Filosofia do Direito, 4 edições, São Paulo, 1953, 1957, 1962, 1965. Assiologia e Normativismo Giuridico; Actes du XI Congrès International de Philosophie, Bruxelles, 1953.

Libertá Antica e Libertá Moderna, no volume "Scritti di Sociologia e Politica in Onore di Luigi Sturzo", Bologna, 1953.

Concreção de Fato, Valor e Norma no Direito Romano Clássico; Ensaio de Interpretação à luz da Teoria Tridimensional do Direito, na "Revista da Faculdade de Direito", v. 49, p. 190-220, São Paulo, 1954.

Avelar Brotero ou a Ideologia sob as Arcadas, na "Revista da Faculdade de Direito", v. 50, p. 131-169, São Paulo, 1955.

Personalismo e Historicismo, na "Revista Brasileira de Filosofia", p. 539 e segs., São Paulo, 1955.

Horizontes do Direito e da História; São Paulo, 1956.

Política e Direito em Roma; a Doutrina de Cícero. São Paulo, 1956.

Direito e Moral. São Paulo, 1956.

Kierkegaard, o seu e o nosso Tempo. São Paulo, 1956.

Dos Planos e Âmbitos do Conhecimento do Direito, São Paulo, 1956. Escolástica e Praxismo na Teoria do Direito de João Mendes Junior, na "Revista da Faculdade de Direito", v. 51, p. 26-73, São Paulo, 1956. 
Giambatista Vico, a Jurisprudência e a descoberta do Mundo da Cultura, na "Revista Brasileira de Filosofia, São Paulo.

Filosofia del Diritto, Trad. dos Professôres Bagolini e Ricci, 1956.

Momentos Decisivos do Pensamento Nacional, Pôrto Alegre, 1958.

Libertà e Valore; (Relatório Especial do XII Congresso Internacional de Filosofia de Veneza) Florença, Ed. Sansoni, 1958; e na "Revista da Faculdade de Direito", v. 53, p. 89-112, São Paulo, 1958.

La Cultura Giuridica Italiana in Brasile, na "Rivista Internazionale di Filosofia del Diritto", nov.-dez., 1958, p. 733-738.

A Filosofia e o Filósofo no Limiar da Era Interplanetária, na "Revista da Faculdade de Direito", v. 54, f. 2, p. 132-139, São Paulo, 1959.

O Problema da Produção na Ideologia Contemporânea, na "Revista da Faculdade de Direito", v. 54, f. 1, p. 178-208, São Paulo, 1959.

A Filosofia no Brasil; (discurso); "Separata" dos "Anais do II Congresso Nacional de Filosofia", p. 9-16, São Paulo, 1959.

La Crisis del Normativismo Juridico y la Exigencia de una Normatividad Concreta no volume "Estudios Juridico-Sociales", homenaje al Professor Luis Legaz y Lacambra, v. 1, p. 187-201, Santiago de Compostela, 1960.

Pedro Lessa e a Filosofia Positiva em São Paulo, na "Revista da Faculdade de Direito", v. 54, f. 2, p. 12-61, São Paulo, 1959 e nos "Anais do III Congresso de Filosofia", p. 91 e segs., São Paulo, 1960.

A Problemática dos Valores no Mundo Contemporâneo, na "Revista da Faculdade de Direito de Sergipe", p. 136 e segs., 1960 e na Revista da Faculdade de Direito" da UsP, v. 56, f. 2, p. 126-145, São Paulo, 1961.

Fundamentos da Concepção Tridimensional do Direito, na "Revista Brasileira de Filosofia”, f. 40, p. 455 e segs., 1960 e na "Revista da Faculdade de Direito", v. 56, f. 2, p. 66-87, São Paulo, 1961.

Filosofia como Autoconsciência de um Povo, na "Revista da Faculdade de Direito", v. 56, f. 2, p. 104-225, São Paulo, 1961.

Fondamenti de la Concezione Tridimensionale del Diritto, na "Rivista Internazionale di Filosofia del Diritto”, f. 2-4, p. 145-163, 1961.

La Filosofia del Derecho y las Formas del Conocimiento Juridico; edição bilingüe da "Revista Juridica de Buenos Aires", com prefácio e tradução do professor Martin Ruiz Moreno, VI, 1961, comemorativa do $500^{\circ}$ aniversário do autor; na "Revista da Faculdade de Direito", v. 57, p. 90-112, São Paulo, 1962 e na "Revista dos Tribunais", a. 51, v. 315, p. 371-385, São Paulo. 
Filosofia em São Paulo; Conselho Estadual de Cultura, 1962.

Law and Power and their Correlation, no volume "Essays in Jurisprudence in Honor of Roscoe Pound", Bobby-Merril Company, in., p. 238-270, 1962.

Aspectos da Teoria Tridimensional do Direito, São Paulo, 1958, 30 págs. inserto depois na $3 .^{a}$ edição de "Filosofia do Direito", 1962.

La Science du Droit selon la Théorie Tridimensionnelle du Droit no Volume "Mélanges en L'Honneur de Jean Dabin", p. 211-230, Paris, 1963.

Pluralismo e. Liberdade, Saraiva S. A. Livreiros Editôres, São Paulo, 1963.

A Teoria Estimativa do Direito. Notas à margem do último livro de Carlos Cossio, na "Revista da Faculdade de Direito", v. 39, p. $136-169,1943 / 44$.

o Direito e o Justo no Crepúsculo da Cultura Helênica, Revista dos Tribunais, 1946.

As três Acepções da palavra Direito, na "Revista da Faculdade de Direito", v. 44, p. 68-78, São Paulo, 1949.

Ontognoseologia, Fenomenologia e Reflexão crítico-histórica, na 'Revista Brasileira de Filosofia", 1966, Fasc. 62.

2. Obras de Teoria Geral do Direito e da Teoria Geral do Estado.

$A$ Crise da Liberdade, na "Tribuna Liberal", órgão do Partido Liberal do Centro XI de Agôsto, junho de 1931.

Fontes do Fascismo, na "A Platéia”, São Paulo, 1933.

Posição do Integralismo, em "Estudos Integralistas”. São Paulo, 1933.

O Estado Moderno, Rio de Janeiro, 1934/35, 3 edições.

Formação da Política Burguesa, Rio de Janeiro, 1934.

O Capitalismo Internacional. Introdução à Economia Nova, Rio de Janeiro, 1935.

Perspectivas Integralistas, Livraria Odeon, São Paulo, 1935.

$A B C$ do Integralismo, São Paulo, 1935/36.

Atualidades Brasileiras, Rio de Janeiro, 1935.

Atualidades de um Mundo Antigo, Rio de Janeiro, 1936.

Direito e Teoria do Estado, na "Revista da Faculdade de Direito", v. 48, p. 84-94, São Paulo, 1953.

O Sistema de Representação Proporcional e o Regime Presidencial Brasileiro, na "Revista Brasileira de Estudos Políticos", v. 3, n. 7, p. 9-44, Belo Horizonte, 1959.

Teoria do Direito e do Estado, $1 .^{\text {a }}$ edição $1940,2 .^{\text {a }}$ edição 1960 , São Paulo.

Nos Quadrantes do Direito Positivo, São Paulo, 1960.

Situation de la Théorie de l'Etat dans les Domaines de la Connais- 
sance Juridique. Traduction de Jacques Douchez. Extraits des Mélanges Paul Roubier, 1953.

\section{Obras sôbre Direito em geral e outros assuntos.}

Claudio Manoel da Costa, o Poeta e o Político: conferência, maio de 1929.

o Valor da Previdência na Formação do Caráter, 1929; (Primeiro prêmio do concurso realizado entre estudantes dos colégios do Estado, publicado na revista "Educação", 1930, n. 3, págs. 254 e segs.)

Sôbre a Coletânea Literária de Rui Barbosa de Batista Pereira, na "Fôlha Estudantina", órgão do Centro Estudantino Dante Alighieri, 1930.

Origem da Religião e Psicanálise, na "Folha Estudantina" do Centro Estudantino Dante Alighieri, 1931.

Byronismo e Álvares de Azevedo no "O XI de Agôsto", p. 11-15, setembro de 1931.

Discurso de Agradecimento por ocasião da posse da Cátedra de Filosofia do Direito na "Revista da Faculdade de Direito", v. 36, p. 23-32, São Paulo, 1941.

O Código de Processo e a Justiça de Paz, na "Revista da Faculdade de Direito". v. 36, p. 667-669, São Paulo, 1941.

Palavras pronunciadas ao tomar posse de Membro do Departamento Administrativo do Estado de São Paulo em 14 de janeiro de 1942, in “Dois Discursos”, p. 23, São Paulo, 1942.

A Exclusão de Sócio das Sociedades Mercantis e o Registro de Comércio in "Ensaios de Filosofia e Direito" Imprensa Nacional, Rio de Janeiro, 1948.

Colonos e Fornecedores. Uma Tentativa de Desorganização da Economia Acucareira Paulista. "Revista dos Tribunais", 1948.

De Dignitate Jurisprudentiae. Oração de Paraninfo aos Bacharelandos de 1951, na "Revista da Faculdade de Direito", v. 46, p. 164-196, São Paulo, 1951.

Direito do Trabalho no Brasil. Discurso Proferido como Delegado Governamental, na $34 .^{\mathrm{a}}$ Sessão da Conferência Internacional do Trabalho de 1951, em Genebra.

Contra a exclusão do Salário Minimo nas Plantações. Discurso sustentando a Emenda do Brasil, que prevaleceu por voto do plenário na Conferência Internacional do Trabalho - oIT (Compte Rendu, 25-6-51).

A Expulsão de Sócio de Sociedade Civil e Contrôle Jurisdicional, na "Revista Forense", a. 50, v. 141, p. 520-525, Rio de Janeiro, 1953.

O Funcionário e seu Direito de Opinião: O Sigilo a que está Adstrito, 
na "Revista dos Tribunais", a. 48, v. 283, p. 44-49, São Paulo, 1959.

Missão do Advogado no Mundo Contemporâneo; na "Revista da Faculdade de Direito", v. 55, p. 106-123, São Paulo, 1960.

A Faculdade de Direito na História do Brasil; Temporalidade Abstrata e Concreta; as Fundações dos Cursos Jurídicos no Brasil em 1827 e sua significação Histórica; o Papel da Jurisprudência nas Primeiras Décadas do Século 19, na "Revista dos Tribunais", a. 5, v. 306, p. 30-39, São Paulo, 1961.

Coexistência da Iniciativa Privada com a Atividade Estatal nos Serviços de Energia Elétrica, São Paulo, 1961.

Sugestões Oferecidas à Reforma do Estatuto da Universidade de São Paulo, na "Revista da Faculdade de Direito", v. 57, p. 286-292, São Paulo, 1962.

Terras Devolutas; Posse e Trabalho, in "Ensaios de Filosofia do Direito", p. 135, s.d., São Paulo.

o Meu Dante; (Conferência Comemorativa do Centenário do Poeta) na "Revista da Faculdade de Direito", v. 60, p. 293-311, São Paulo, 1965.

Renovação do Direito Moderno, in "Ensaios de Filosofia do Direito", p. 127, s.d., São Paulo.

Diretrizes da Política Agrária Paulista - Ed. da Imprensa Oficial do Estado, São Paulo, 1963.

As Cátedras Universitárias e seu Provimento, in "Revista dos Tribunais", a. 52, v. 327 , p. $43-49$, São Paulo.

Poemas do Amor $e$ do Tempo, Saraiva Sociedade Anônima Livreirós Editores, São Paulo, 1965.

\section{Principais Estudos sôbre a Obra de Miguel Reale.}

\section{Em Livros:}

Tristão de Athayde, Meditação sôbre o Mundo Moderno, p. 85-93, Rio de Janeiro, 1943.

José L. Kunz, (Professor of Law, University of Toledo, Ohio) - in "Latin American Philosophy of Law in Twenty Century", p. $30-31,1950$.

Hermes Lima, (da Universidade do Brasil) - Introdução à Ciência do

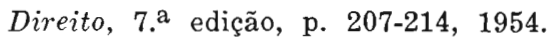

Paulo Dourado de Gusmão, (da Universidade do Brasil) - O Pensamento Jurídico Contemporâneo, p. 61-67, São Paulo, 1955.

Renato Cirell Czerna (da Universidade de São Paulo) - A Filosofia Jurídica de Benetto Croce, p. 36-69, São Paulo, 1955.

EdGard de Godor da Mata Machado (da Universidade de Minas Gerais) - Direito e Coerção, p. 57-63, Belo Horizonte, 1956. 
A. L. Machado Neto, Sociedade e Direito, Livraria Progresso Editora, p. 205-210, Salvador, 1957.

Luis Washington Vita, Namôro com Thémis, p. 130 e segs. e passim., São Paulo, 1958.

Luis ReCaséns Siches, Tratado General de Filosofia del Derecho, p. 157 e segs., México, 1959.

PEDRo R. DAVID, Dos Concepciones del Derecho Integrativas: Hall $y$ Reale, nos "Anais do III Congresso Brasileiro de Filosofia", p. 257 e segs., São Paulo, 1960.

A. L. Machado Neto, Introdução à Ciência do Direito, ed. Saraiva, v. 1, p. 36 e segs. e passim. e 61 e segs., 1960.

Paulo Dourado de Gusmão, Introdução à Ciência do Direito, $2 .{ }^{a}$ edição, p. 440 e segs., Rio de Janeiro, 1960.

Pe. Henrique C. de Lima Vaz, O Pensamento Filosófico no Brasil de Hoje, p. 19 e segs., Braga, 1961.

L. ReCaséns Siches, Panorama del Pensamiento Juridico en el Siglo XX, v. 1, p. 553-567, Editorial Parma S.A., México, 1963.

Wilson Chagas, Conceito Finalístico do Direito, Capítulo I e passim., Pelotas, 1964.

Drno Pasini, Vita e Forma nella Realtà del Diritto, Milão, 1964, passim.

Ferrater Mora, Diccionario de Filosofia, 5. ${ }^{\text {a }}$ ed., Editorial Sudamericana de Buenos Aires, 2. ${ }^{\circ}$ volume, p. 537, 1965.

Gruseppe Lumia, Il Diritto tra le Due Culture, p. 46 e passim., Milão, 1966.

Cabral DE Moncada, Filosofia do Direito e do Estado, $2 .^{\circ}$ volume, p. 115 e segs., Coimbra, 1966.

\section{Em Revistas e Jornais:}

Luigr Bagolini, (da Universidade de Genova) - Filosofia del Diritto "Revista de Estudios Americanos", Sevilha. 1953, n. 25, p. 277293 e na "Revista da Faculdade de Direito", 1952.

Luigr Bagolini, (da Universidade de Genova) - Filosofia del Diritto in Brasile, na "Rivista Internazionale de Filosofia del Diritto", 1954, f. 3, p. 412-417.

Luigr Bagolini, Problemi di Filosofia del Diritto in Brasile, em "Studi Senesi", 1952, f. 1-2.

Josef L. Kunz, Zur Problematik der Rechtsphilosophie um die Mitte des Zwanzigsten Jahrhundert, na "Osterrzeitschrift fur Offentliches Recht”, Viena, f. I, 1951. Há tradução portuguêsa do prof. Genésio de Almeida Moura, na "Revista da Faculdade de Direito da| Universidađe de São Paulo", v. 46, 1951, p. 5-43.

JOSEF L. KUNZ, Latin-Amerikanische Rechtsphilosophie in "Zwanzigsten Jahrhundert” (Arch. fur Rechts-und Sozialphilosophie). 
Josef L. KunZ, Contemporary Latin-American Philosophy of Law "The American Journal of Comparative Law", v. 3, n. 2, p. 212 e segs., 1954.

Agustin DE Asis GaRrote (Da Universidade de Sevilha) - La Filosofia General del Derecho de Miguel Reale, na "Revista de Estudios Americanos", Sevilha, 1954, n. 32, p. 384-403.

Luis Recaséns Siches (da Universidade Autônoma de México) - Re senha bíbliográfica em Dianóia, do livro Horizontes do Direito e da História, "Anuário de Filosofia da Universidade do México", 1957, n. 3, p. 404-406.

GOFREDo QUADRI, Resenha Bibliográfica na "Rivista Internazionale di Filosofia del Diritto", 1955, f. 6, p. 839-840.

Ilmar Tamello, (da Universidade de Melbourne, Austrália) - resenha bibliográfica da obra Filosofia do Direito na "Sidney Law Review", 1955, v. 1, p. 444-446.

Pier LUigi Zampetti, Su un'opera brasiliana di Filosofia del Diritto em "Jus", Rivista della Università Cattolica del Sacro Cuore, p. 146-71, Milão 1957.

Glaucio Veiga, (Da Universidade de Pernambuco) - Sôbre um livro de Miguel Reale, Horizontes do Direito e da História, na "Revista Brasileira de Filosofia", n. 56, v. 6, f. 2, p. 224-235.

B. Mantilla Pineda, (Da Universidade de Antioquia-Colombia) - La Teoria Tridimensional del Derecho de Miguel Reale, "El Colombiano Leterario", Medellin, Colombia, 29 de abril de 1956, Transcrito na "Revista Brasileira de Filosofia", 1956, f. 4, p. 570-6.

Miguel Herrera Figueroa, (Da Universidade de Tucuman-Argentina) - Miguel Reale Filosofo y Jurista, em o "Norte Universitário", Tucumán, 9-6-56. Transcrito na "Revista da Faculdade de Direito de São Paulo", 1955, p. 376-8.

Miguel Herrera Figueroa, Resenha Bibliográfica na "Revista da Faculdade de Direito" da Universidade de São Paulo, 1954, p. 466-72 sôbre Filosofia do Direito, $1 .^{\mathrm{a}}$ edição.

Vittorio Frosini, (da Universidade de Messina) - Resenha Bibliográfica na "Rivista Internazionale de Filosofia del Diritto", 1957, f. 1 .

Renato Crrell Czerna, (da Universidade de São Paulo) - Sul pensiero Filosofico-Giuridico di Miguel Reale, na "Rivista Internazionale di Filosofia del Diritto", Set.-Out. 1957, f. 5, p. 637 e segs..

Renato Cirell Czerna, Criticismo Ontognoseológico e Tridimencionalidade, na "Revista Brasileira de Filosofia", jan.-março 1955, p. 73 e segs., inserto no volume "Ensaio de Filosofia Social e Jurídica" (Direito e Comunidade) São Paulo, 1965. 
Joaquim de Carvalho, (da Universidade de Coimbra) - resenha bibligráfica na "Revista Filosófica", n. 8, 167-171 Coimbra, 1953, sôbre Razão de Estado no Renascimento Lusitano.

Agustin de Asis Garrote, (da Universidade de Sevilha) - La Filosofia del Derecho em Hispano América na "Revista de Estudios Americanos", 1955 , n. 44 , p. 467 e segs.

Agustin De Asis Garrote - La Filosofia General de Derecho de Miguel Reale na "Revista Estudios Americanos", n. 32, p. 384-403, Sevilha, 1954.

Ivanhoe Tibaldeschi - Diritto e Attivitò Umana nel Pensiero di Miguel Reale, na "Rivista Internazionale di Filosofia del Diritto", v. 5, p. 645-649, 1957.

Arthur ChILD, (da Universidade de Los Angeles) - Resenha Bibliográfica na "Philosophy and Phenomenological Research", v. 7, p. 172-175, 1946.

LEONARDo VAN ACKer - Resenha Bibliográfica na Folha da Manhã, Reproduzida na "Revista Brasileira de Filosofia", f. 26-1956.

Waldemar Ferreira - Resenha bibliográfica da Filosofia do Direito na "Revista da Faculdade de Direito" de São Paulo, v. 49, p. 472-3, 1954.

Plínio Barreto - Resenha Bibliográfica em "O Estado de São Paulo" de 30-12-1963.

Vicente Ferreira dA Silva - Resenha Bibliográfica no Diário de São Paulo de 10-12-53.

Renato Cirell Czerna - Resenha Bibliográfica na "Folha da Manhã" de 18-12-53.

Teófilo Cavalcanti Filho, Resenha Bibliográfica na Folha da Manhã de 29-11-1953.

Bragio de GrovanNi - Resenha Bibliográfica à Tradução Italiana de Filosofia do Direito, Universitá Degli Studi di Napoli, no "Bollettino", III, p. 204-206, 1957.

Odilon da Costa Manso - Resenha Bibliográfica no "Correio Paulistano" de 23-3-1958.

Luis LuisI, da Universidade do Rio Grande do Sul - Filosofia do Direito no Brasil, 1-5-1957.

Osmar Pimentel - Resenha sôbre A Doutrina äe Ǩant no Brasil na "Folha da Manhã"

CÂNoido MotTa Filho, Resenha Bibliográfica no "Diário de São Paulo" de 3-1-1954.

Jamil Almansur Haddad, Resenha Bibliográfica na "Revista Brasileira de Filosofia", 1956, f. II, p. 284 e segs..

JAMIL ALMANSur HADDAD, Resenha Bibliográfica sôbre a 2. ${ }^{\mathrm{a}}$ edição de Filosofia do Direito no "Correio Paulistano" de 19-12-1957. 
José Frederico Marques, Resenha Bibliográfica em "O Estado de São Paulo" de 9-12-56.

Carlo CuRcio - Resenha do livro Horizontes do Direito e da História, na "Rivista Internazionale di Filosofia del Diritto", 1956, v. 6, p. 806-807.

GiUseppe Meironi, Resenha do estudo Direito e Teoria do Estado, na "Rivista Internazionale di Filosofia del Diritto, 1956, v. 6, p. 807.

Almeida Magalhães, Resenha do livro Doutrina de Kant no Brasil na "Folha da Manhã" de 26-3-49 e de 2-4-49.

Candido MotTa Filho, Crítica do Livro Doutrina de Kant no Brasil no "Diário de São Paulo" de 24-4-49.

Luis Washington Vita, Resenha do Livro A Doutrina de Kant no Brasil no "Diário de São Paulo" de 6-3-1949.

- Universo Realeano, na "Rev. Bras. de Filosofia", 1964, fasc. 52, págs. 535-550.

A. L. Machado Neto, Crítica da Filosofia do Direito, $1 .{ }^{\text {a }}$ edição, no "Diário de São Paulo" de 16-5-1954.

Guido Fassó (da Universidade de Catania-Itália) - Resenha da "Rivista di Procedura Civile" de Dezembro de 1957.

Antonio Falchi, La Teoria Tridimensionale del Diritto na "Rivista Internazionale di Filosofia del Diritto", 1961, f. 5, p. 517 e segs.

Silvana Castignore, Resenha à $3 .^{\text {a }}$ edição da Filosofia do Direito, na "Rivista Internazionale di Filosofia del Diritto", julhoOutubro, 1963, p. 633-636.

ERnesto Leme, Discurso de saudação na entrega do Prêmio Moinho Santista ao Prof. Miguel Reale, na "Revista da Faculdade de Direito" v. 60, p. 346 e segs., São Paulo, 1965.

José Cretella Junion, Pluralismo e Liberdade de Miguel Reale, na "Revista Brasileira de Filosofia", f. 57, p. 70 e segs., São Paulo, 1965.

Francis Lamand, Le Fait et le Droit, na "Révue de Métaphysique et de Morale", 1966.

\section{Trabalhos Forenses:}

Agravo de Petição n. 23.382 da Capital: minuta do agravante. Emprêsa Gráfica da Revista dos Tribunais Ltda., São Paulo, 1944.

Apelação 23.948 da Capital (razões); Revista dos Tribunais, São Paulo, 1944.

Um Caso de Direito de Vizinhança; apelação civel 23.948 da Capital (razões); Revista dos Tribunais, São Paulo, 1944. 
Executivo hipotecário: propriedade agricola adquirida com pacto adjeto de hipoteca; prestação imperfeita do vendedor: consultas e pareceres; in Revista dos Tribunais, São Paulo, 1956, v. 254, p. $16 / 23$.

Em defesa do regimento da Câmara Municipal; apelação cível n. 44.149 da capital (razões); Emprêsa Gráfica da Revista dos Tribunais, São Paulo, 1949.

A autonomia do Município e a intangibilidade de seu território: representação das Municipalidades de Presidente Venceslau e Marabá Paulista, São Paulo, Revista dos Tribunais, 1955.

O Colono Paulista e o I.A.A. (razões); São Paulo, 1945.

Da cláusula CIF. Recurso Extraordinário n. 8.177 (razões); Revista dos Tribunais, São Paulo, 1944.

Direitos e Deveres dos Acionistas: da validade dos contratos de venda de ações, com renúncia de direito de voto e dividendo; Revista dos Tribunais, São Paulo, 1946, 1. ${ }^{\circ}$ volume.

Do Direito dos ex-acionistas à verificação dos lucros sociais (memorial) in Ação Ordinária, São Paulo, 1949, 2. ${ }^{\circ}$ volume, p. 101.

Exame de livros de terceiros; embargos no mandato de segurança n. 40.577 da capital, Revista dos Tribunais, São Paulo, 1949.

Expulsão de sócio de sociedade civil e contrôle jurisdicional; in Revista Forense, Rio de Janeiro, 1953, v. 141, p. 520-525.

Nulidade de pleno direito de cláusulas contratuais que implicam renúncia pelo acionista do direito ao dividendo $e$ ao voto (memorial); in Ação Ordinária, São Paulo, 1949, 2. ${ }^{\circ}$ volume, p. 127.

Pátrio Poder, guarda dos filhos; situação prevista em desquite e faculdade assegurada ao juiz de regulá-la. diferentemente nos termos do art. 327 do código civil. Ampliação dêsse preceito ao caso de dissolução do casamento por morte de um dos cônjuges; inadmissibilidade; in Revista dos Tribunais, São Paulo, 1943 , v. 145 , p. $20 / 28$.

Da responsabilidade do engenheiro na empreitada de simples lavor; apelação cível 20.348 (razões), São Paulo, 1943.

Sôbre cheques sem fundos; agravo de petição n. 23.382 da Capital in Revista dos Tribunais, São Paulo, 1944.

Tentativa de enriquecimento ilícito; apelação n. 43.471 da Capital; (razões) in Revista dos Tribunais. São Paulo, 1949.

As usinas de açúcar e o impôsto de renda (razões); in Revista dos Tribunais, São Paulo, 1945.

Exame de livros de terceiros: embargos no mandado de segurança n. 40.577 da capital. Emprêsa Gráfica da Revista dos Tribunais Ltda., São Paulo, 1949. 


\section{Pareceres:}

Doação de bens patrimoniais pelos Municipios; regras interpretativas da competência do poder público; in Ensaios de Filosofia do Direito, p. 151.

Mandado de Segurança: direito líquido e certo; interpretaçāo da expressão; certeza do fato; solução jurídica por mais intrincada que seja; obscuridade possivel da lei; natureza subjetiva que, em suma, deve ter liquidez ou a certeza do direito; in Revista dos Tribunais, 1953, v. 42:213, p. 56/69.

Município, criação, natureza jurídica; limites do poder do estado federado; direito ao território; in Revista Forense, Rio de Janeiro, 1955, v. 162 , p. $71 / 77$.

Da natureza jurídica das entradas adicionais feitas pelos subscritores das sociedades anônimas (memorial); in Ação Ordinária. São Paulo, 1949, 2. ${ }^{\circ}$ v., p. 11.

$O$ problema jurídico da criação dos municipios; a propósito $-\vec{\alpha}$ projetada criação do Municipio de Adamantina; in Ensaios de Filosofia e Direito, São Paulo, 1948, p. 57.

Da recorribilidade dos despachos do Diretor Geral do Departamento de estradas de rodagem; mandado de segurança $51.923 \mathrm{da}$ Capital; Revista dos Tribunais, São Paulo, 1950.

Sentença Criminal; efeitos civis em matéria de fato ou de autoria: da inversão do "onus probandi" no juízo civil quando ela é absolutória; inteligência do art. 66 do Código de processo penal; in Revista dos Tribunais, São Paulo, 1952, a. 41, v. 201, p. 62/68.

Sociedade Civil; associações de classe; contrôle judicial dos atos disciplinares praticados contra associados; teorias a respeito; eliminação de sócio que dirigiu cartas injuriosas e caluniosas à diretoria; observância das leis e dos estatutos; in Revista dos Tribunais, 1953 , v. $42: 214$, p. $25 / 35$.

Sociedades comerciais; exclusão de sócios; atribuições das Juntas comerciais; in Revista Forense, Rio de Janeiro, 1944, v. 98, p. 561.

Veto; inconstitucionalidade; matéria de iniciativa do poder judiciário e aprovado pelo poder legislativo; aumento de vencimentos dos funcionários do Tribunal de Justiça; inteligência do art. $97 n$. I da Constituição Federal; in Revista dos Tribunais, 1953, v. 42-212, p. 16-23.

Vínculo; do valor da cláusula de impenhorabilidade dos frutos e rendimentos dos bens inalienáveis, ante o disposto no art. 943, n. I do Código de processo civil; in Revista dos Tribunais, São Paulo, 1951, a. 40, v. 189-609, p. 605-608. 
Concorrência Pública; as normas do código de contabilidade pública em matéria de concorrência; in Revista dos Tribunais, São Paulo, 1959, a. 48, v. 284, p. 43-50.

Da interrupção de prescrição segundo o estatuido no $\S 2 .^{\circ}$ do art. 166 do código de processo civil e comercial; in Revista dos Tribunais, São Paulo, 1961, a 50, v. 310, p. 45-50.

Desapropriação, ações de sociedade anônima, concessão de serviço público; in Revista Forense, Rio de Janeiro, a. 59, v. 200, p. 51-58.

Desapropriação; mandado de segurança; sociedade anôima; encampação de serviços públicos concedidos; desapropriação; in Re. vista dos Tribunais, São Paulo, 1962, a. 51, v. 315, p. 628-690.

Dividas de jôgo; entendimento do art. 1477 do código civil; se configura nulidade ou mera inexigibilidade... in Revista dos Tribunais, São Paulo, a. 46, v. 264, p. 87-93.

Do contrôle de constitucionalidade através de representação ao Supremo Tribunal Federal; in Revista dos Tribunais, São Paulo, 1959, a. 48 , v. 281, p. $61-69$.

Esbulho; má fé; ressarcimento de benfeitorias necessárias; abuso de direito; in Revista Forense, 1957, a. 54, v. 173, p. 121-125.

Os funcionários públicos e os serviços de guerra; sentido das leis federais que outorgaram vantagens aos militares em serviço na "zona de guerra" in Revista dos Tribunais, São Paulo, 1960 , a. 49 , v. 294 , p. $40-48$.

Instituto Brasileiro do Café; constituição das juntas administrativas; in Revista dos Tribunais; São Paulo, 1949, a. 48, v. 286, p. 35-42.

Lei de Divisão Judiciária; proposta de iniciativa do judiciário e competência do legislativo; in Revista dos Tribunais, São Paulo, 1957 , a. 16, v. 263, p. $32-35$.

Natureza Jurídica da "Fundação de Amparo à Pesquisa do Estado de São Paulo", in Revista da Faculdade de Direito, São Paulo, 1962, v. 57, p. 255-266.

Prova: testemunha: preposto: impedimento legal: quando ocorre: distinção entre impedimento $e$ inidoneidade $\grave{a}$ luz do art. 240 do código de processo. Responsabilidade civil: do nexo de causalidade: insuficiência de mera culpa: causa adequada $e$ relação fortuita.. in Revista dos Tribunais. São Paulo, 1951, a. 40 , v. 194, p. 53-63.

Contrato bilateral; in Revista dos Tribunais, 1955, v. 44-232, p. 43-50. Quimico, regulamentação do exercício da profissão; in Revista Forense, Rio de Janeiro, 1958, a. 55, v. 178, p. 99-103. 
Kevogação e anulamento de ato complexo; in Revista dos Tribunais, São Paulo, 1964, a. 54, v. 348, p. 37-51.

Vinculo: da cláusula de inalienabilidade. Especificidade do problema. no direito pátrio; cláusula de inalienabilidade sôbre a legítima e o disponivel; in Revista dos Tribunais, São Paulo, 1959, a. 48 , v. 290 , p. $49-57$.

Condominio; natureza jurídica; incorporaçāo de edificio de apartamentos; in Revista Forense, Rio de Janeiro, 1952, a. 49, v. 139, p. $72-76$. 